\title{
An Empirical Investigation of Teacher Trainers' Perspective of Teaching and Learning Environment Existing in Selected Colleges of Education in Zambia
}

\author{
Sr. Trinity Rose Chikwanda*, Dr. Gift Masaiti \\ University of Zambia, School of Education, Lusaka - Zambia
}

*Corresponding Author: Sr. Trinity Rose Chikwanda, University of Zambia, School of Education, Lusaka-Zambia

\begin{abstract}
This study investigated teacher trainers' perspective of the type of environment existing in two private and two government Colleges of Education in Zambia. A mixed research approach and correlation design was used to investigate teacher trainers' perspective of what teaching and learning environment existed in their colleges. A sample of 96 teacher trainers was randomly and purposively selected from the four colleges. Data were collected using questionnaire, Focus Group Discussion, semi- structured interview and observation. Data analysis involved using interpretivism and positivism paradigms as well as STATA software for quantitative data while qualitative data were analyzed manually using emerging themes. The findings indicated that teacher trainers considered poor to moderate environment to be existing in their respective colleges which had repercussions on teaching and learning. This environment had strong links with leadership styles used to administer colleges. The use of autocratic, laissez-faire and democratic leadership styles contributed to creation of poor to moderate environments while instructional produced moderate to high or good teaching and learning environment. It is therefore recommended that Principals must choose leadership styles which would enhance creation of conducive teaching and learning environments in their respective institutions to improve college academic performance.
\end{abstract}

Keywords: Conducive environment, leadership styles, effective teaching and learning

\section{INTRODUCTION}

Every organization desires to work in a conducive and healthy environment for it to excel in its operations. Institutions of learning too desire to have a free, friendly and supportive environment which is free from intimidation and emotional frustrations. This kind of environment when it prevails encourages members to work with a free mind and put in their best which results in high productivity and meritorious performance in various aspects of college life. This study sought to investigate teacher trainers perception of the type of environments existing in two private and two government owned Colleges of Education (CoE) in Zambia so as to determine whether such environment induce effective teaching and learning (T/L). This term conducive environment has no universal definition but Khalid (2008) describe conducive environment as an environment where levels of co-operation, networking and collaboration among staff, students and administrators are high.

The creation of this environment is not a days' work nor is it one man's show. Oyetunji (2006) elucidated that creating a positive climate (environment) required the collective efforts of the leader, teacher educators, learners and other stakeholders found in the institution. However, many researchers (Oyetunji, 2006, McBeath \& Myers, 2008, Nsubuga, 2008, Wiza \& Hlanganipai, 2014, Puni, Ofei and Okoe, 2014, Kumar, 201814) have plainly put it that the leader plays a critical role in the creation of this enabling working environment. This he/she does by employing a particular leadership style(s) in his/her work. The style chosen can either enhance creation of conducive teaching and learning environment or can thwart it. Thus four leadership styles namely autocratic, democratic, laissez-faire and instructional were examined to ascertain their contribution to T/Lenvironments prevailing in selected Colleges of Education (CoE) in Zambia.

\section{Statement of Problem}

Researches (Oyetunji, 2006, Khalid, 2008, Nyeri, 2015) conducted on conducive environment in institutions of learning have not addressed the situation in Colleges of Education which have 
multiplier effect on what happens in schools, since the colleges train teachers who work in these schools. This study sought to investigate teacher trainers' perception of what type of T/L environments exist in $\mathrm{CoE}$, in order to facilitate good academic performance, and how such environments influence $\mathrm{T} / \mathrm{L}$ in selected private and government colleges in Zambia.

\subsection{Significance of the Study}

The study conducted served as a valuable contribution to the existing body of knowledge in the area of teaching and learning environment existing in Colleges of Education in Zambia. It also served as a basis for further studies that may help to develop conducive $\mathrm{T} / \mathrm{L}$ environments which may be more applicable to the college context. The study is likely to render Principals an opportunity to use the data as baseline for their own reflective purposes on how they run their institutions and what kind of $\mathrm{T} / \mathrm{L}$ environment is developed through the type of leadership they provide in their institutions. But most importantly the findings may provide lessons to draw on by Ministry of Education (MoE) policy makers who may be helped to plan how best colleges may be helped to address the issue of T/L environment prevailing in $\mathrm{CoE}$ in Zambia.

\subsection{Objective}

To examine teacher trainers' perception of $\mathrm{T} / \mathrm{L}$ environment prevailing in selected $\mathrm{CoE}$ so as to determine their contribution to teaching and learning.

\subsection{Research Question}

What impact does the environment existing in selected CoE in Zambia have on teaching and learning?

\section{LITERATURE REVIEW}

The literature reviewed has not given a universal or straight forward definition for the term conducive T/L environment. OECD (2009) define conducive environment as the support systems that create conditions in which human beings learn best. This definition entails putting in place systems that accommodate the unique learning needs of every learner and underpin the human relationships which are needed for effective teaching and learning to take place (ibid).The term conducive environment can be understood from two dimensions that is by examining the physical environment which among others includes physical space, buildings and how the buildings are furnished as well as whether the buildings (classrooms) are spacious enough and well ventilated. The other dimension involves the atmosphere in an institution which encompasses free interaction among college members, the cooperation and collaboration existing, how conflicts are resolved and the respect accorded to each member found in the institution. Arguably the physical environment does not constitute conducive $\mathrm{T} / \mathrm{L}$ environment. Observations have revealed that some well-furnished physical spaces with a lot of resources do not constitute conducive T/L environments and hence do not attract good academic performance. Whilst some dilapidated schools create conducive T/L environment. However, as OECD (2009) put it that while the building alone does not make $21^{\text {st }}$ century school; common sense suggests that the quality of where we learn affects the quality of how we learn. This implies that creating a conducive $\mathrm{T} / \mathrm{L}$ environment commences with creating a good physical space that is able to accommodate learners and staff, and which permit all stakeholders to interact freely without limitation.

Nevertheless, it is on the second dimension where this study is anchored. Conducive environment which institute free, good and safe atmosphere and which attract good neighborliness affect positively what takes place in the classroom. When good relationship exist between administrators, staff and students, it would be easy for administrators to provide resources needed and furnish class room space for effective teaching to occur. Wiza \& Hlanganipai (2014) contended that the responsibility of education leadership is to facilitate the learning activities and provide an environment that is enabling and supportive for requisition of knowledge. This is possible where good rapport between administrators and staff exists and where Principals understand their role of creating conducive environment for effective T/L.

Researchers conducted by some researchers (Oyetunji, 2006, Nyeri, 2015) have revealed that institutions of learning particularly schools have been operating in contexts which do not facilitate creation of conducive environment for effective T/L to be taking place. One of the factors identified for this shortcoming is the type of leadership provided in these institutions. The leadership style as Levin (2001) put it determines the success and productivity of the institution. While other factors such as behavior of subordinates, finances and school culture may influence creation of conducive T/L but 
leadership plays a key role in what takes place in a learning institution. In addition the behavior and practices of the leader impacts subordinates' performance which in the end affect creation of positive $\mathrm{T} / \mathrm{L}$ environment. This scenario has repercussions on how $\mathrm{T} / \mathrm{L}$ takes place as well as academic performance of students. This explanation fits in Path-Goal Theory which informed the study. The theory explains how the behavior of the leader motivates or demotivates followers and thus influences the performance and satisfaction of the followers in an institution.

\section{Methodology}

\subsection{Research Design and Sampling}

In order to understand teacher trainers perception of the type of environment existing in CoE, a correlation design and mixed research approach was purposively selected which is the procedure of collecting and analyzing both qualitative and quantitative data in a single study (Creswell, 2012). The rationale for choosing this design was that combining the two approaches provided more insight and understanding of the phenomenon that might have been missed when only one single research design was used (ibid). The study engaged 96 ( 44 males and 52 females) teacher trainers as research participants that is 26 from private and 70 from government owned colleges, who were culled using simple random and purposive sampling techniques. Data were collected using questionnaires which was self-made, semi-structured interview guide, Focus Group Discussion (FGD) and observation. Collection of data was preceded by getting ethical clearance from the University of Zambia Ethics Committee after meeting the requirements. To access Provinces, clearance was also sought from the Permanent Secretary (PS) of the Ministry of General Education to which colleges belong. To access colleges, permission was obtained from Principals as leaders of the colleges.

\subsection{Data Collection and Analysis}

Data were collected in two phases at both private and government colleges commencing with qualitative data. This was followed after a year with quantitative data after realizing gaps in the qualitative data. An explanatory sequential design was used to analyze data which required analyzing quantitative data first and supporting it with qualitative data. Hence data were analyzed using positivism (for quantitative) and interpretivism (for qualitative) paradigms. This was done to make the findings more authentic and reliable. Quantitative data were analyzed using STATA software (version 14) and Pearson chi 2 to get frequency tables and inferences. Qualitative data were analyzed using thematic approach to garner the required lived experiences of teacher trainers in their respective colleges.

Ethical considerations were strictly adhered to by explaining the purpose of study to participants first and enlightening them on their right to participate or withdraw if they so wished to. It was only after an agreement had been reached that the consent form was signed. The principle of anonymity and confidentiality were strictly adhered to by not disclosing the names of colleges and participants and not disclosing information gathered to any other persons but used it for the intended purpose.

The validity was guaranteed by using multiple data collection techniques, requesting member checking of what had been collected and triangulating the data collected. Reliability was also guaranteed by the long period of three weeks spent on each site to collect data and collecting data in two phases after a year. The getting of the same responses after a year made data collected to be reliable.

\section{FINDINGS AND DISCUSSION}

\subsection{Conducive T/L Environment Bar Chart}

The findings of the study presented in the above bar chart revealed that teacher trainers considered the environment existing in their colleges to be poor to moderate which had negative consequences on teaching and learning. The bar chart illustrates the responses of the participants. Seven tenets were used to measure the existence of conducive T/L environment. The tenets were categorized as follows: an average of one to two scores out of seven variables meant the environment was poor. Three to four score was moderate (Average) while five to seven meant the environment was high and very conducive for T/L.

The chart depicted that $61(63.54 \%)$ teacher trainers described the environment to be poor, while $31(32.29 \%)$ considered it to be moderate and only four (4.17\%) regarded it to be high (good) and conducive for effective teaching and learning. The poor environment stated by the majority implied that lecturers were working under unfavorable conditions which they did not like. It meant the atmosphere was not free and friendly but was frustrating, intimidating and emotionally disruptive 
which affected the way they offered lectures and negatively influenced the way students acquired learning. Lecturers condemned the atmosphere in which they worked which they said was tense and not offering good interaction amongst themselves and their administrators. The poor environment meant they were not being involved in the running of the colleges thus felt disconnected. But Wiza \&Hlanganipai (2014) posit that it is the responsibility of the educational leader to provide an environment that is enabling and supportive for learning.

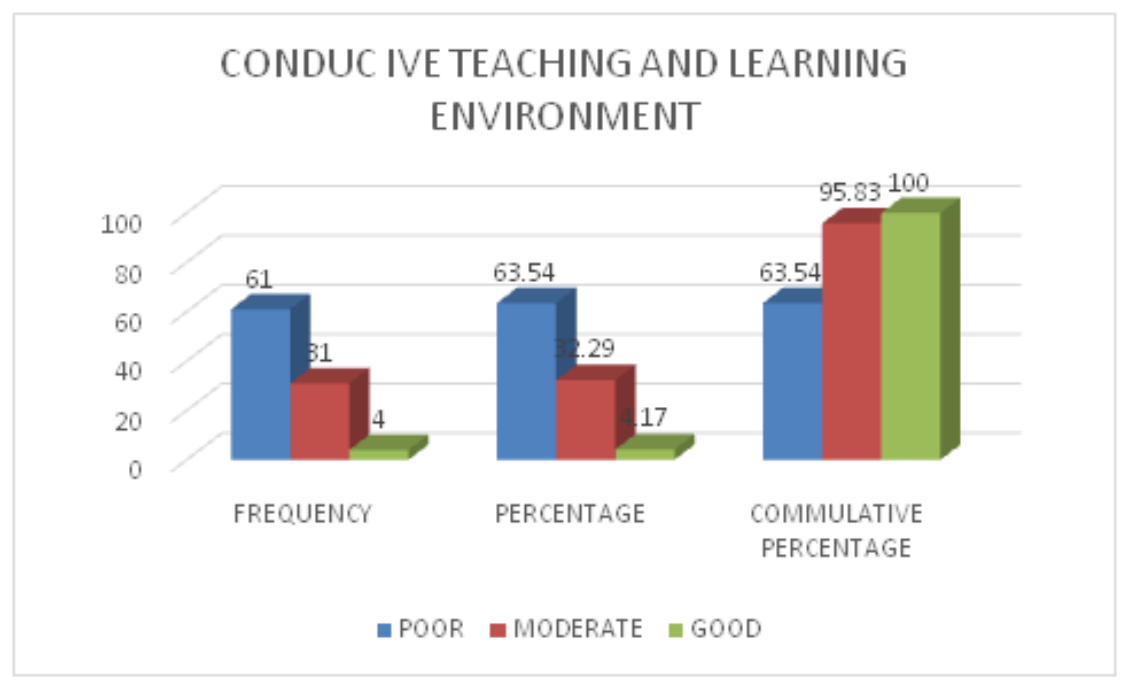

The poor environment was also attributed to leaders' failure to unite all members, to involve all members in decision making, to consult so as to give them all the sense of ownership of whatever undertakings in the college. Their responses were corroborated by qualitative data where during interviews it was categorically stated that the environment was not conducive because of the leadership of their Principals. One responded said "the environment is not good because we work under intimidation. The Principal uses threats to frighten whoever wants to challenge his decisions." Another intimated that "Leadership prevailing in this institution does not help to create conducive T/L environment because what we do is the ideas of one person, the Principal does not consult us especially us ordinary lecturers, he does not even hold staff meetings where we can air out views." These sentiments supported what had come out from quantitative data.

The 31 lecturers who described the environment to be moderate or average meant that though the environment was not so good, but they were surviving and fairly happy with the way things were happening in their respective colleges. It meant that though the situation or atmosphere was not very free or friendly but teaching and learning were taking place effectively. One respondent during interview highlighted that "the leadership is not so good. It is good in some ways and not good in other ways thus even the environment is so and so. It is conducive in some ways and not conducive in other ways." The implication was that how teacher trainers expected things to be in the college was not always according to their expectations. This meant good environment was fluctuating but they just accepted the situation the way it was. It also meant that there was no consistence in the way colleges were being administered.

The four lecturers who considered the environment to be high (good and conducive) were happy with the way colleges were being administered. They considered Principals to be doing things according to their expectations. They (Principals) allowed members to interact freely and encouraged collaboration in the way they worked. These could have been close to the Principals and who were often involved in whatever their Principals were doing. During FGD one respondent asserted that "the environment is good in this institution because we work together, our Principal is inclusive he brings everyone on board." These sentiments revealed how some teacher trainers perception was though these sentiments were contrary to what the majority said.

One of the factors singled out to play an important role in setting the tone of the environment existing was the type of leadership. Ojokuku, Odetayo and Sajuyigbe (2012) opined that leadership determines the success or failure of an institution. Participants in the study highlighted that the type of leadership prevailing has serious repercussions on creation of conducive $\mathrm{T} / \mathrm{L}$ environment. The information below showed the results of the leadership styles studied. 
An Empirical Investigation of Teacher Trainers' Perspective of Teaching and Learning Environment Existing in Selected Colleges of Education in Zambia

\subsection{Leadership Styles and Conducive T/L Environment}

\begin{tabular}{|l|l|l|l|l|l|l|l|}
\hline L/ Style & F & Low\% & F & Average\% F & High\% & Total \\
\hline Autocratic & 50 & 75.76 & 15 & 22.73 & 1 & 1.52 & 66 \\
\hline Democratic & 6 & 26.09 & 14 & 60.87 & 3 & 13.04 & 23 \\
\hline Laissez-faire & 2 & 2.13 & 0 & 0 & 0 & 0 & 2 \\
\hline Instructional & 2 & 2.13 & 1 & 1.52 & 0 & 0 & 3 \\
\hline Total & 60 & 63.83 & 30 & 31.91 & 4 & 4.26 & 94 \\
\hline
\end{tabular}

Pearson chi2 (6) $=20.9973 \mathrm{Pr}=0.002$

The results indicated that there was a significant correlation between leadership styles and creation of conducive $\mathrm{T} / \mathrm{L}$ environment. While the chi 2 of $\mathrm{P}=0.002$ when $\mathrm{P}$ is significant at 0.005 level of confidence implied that leadership styles were correlated to conducive teaching and learning environment, the results showed negative environment for autocratic, laissez-faire and democratic leadership style where the environment is described as poor to moderate. It is only with instructional leadership style where a moderate to slightly positive environment existed. This presentation simply meant that the style of leadership chosen and how it was used determine the type of environment existing in $\mathrm{CoE}$ in Zambia.

The investigation on the type of environment existing in the two types of colleges revealed that being government or private had no significant relationship to creating conducive T/L environment. The Pearson chi2 of $\mathrm{P}=-0.679$ when $\mathrm{P}$ value is significant at 0.005 indicated that the category of colleges had no correlation to creating of conducive T/L environment. This showed that both colleges had poor to moderate $\mathrm{T} / \mathrm{L}$ environments.

\section{CONCLuSion}

The research had highlighted that poor to moderate environment existed in selected CoE in Zambia. The creation of this type of environment was dependent on the leadership provided in the institution and expressed in the behavior of the Principal leading the institution. This fits in the Path-Goal Theory used in this study which states that the behavior of the leader motivates and satisfies subordinates and encourages them to perform well when it fits the expectations of subordinates. But it is a source of demotivation and poor performance when the leader's behavior does not correspond with subordinates characteristics and task being performed. This study has therefore established that the environment existing in selected colleges was poor to moderate which had negative repercussions on how teaching was being conducted by teacher trainers and learning was being received by students in these colleges. It can therefore be stated that there was a correlation between leadership style in use and creation of $\mathrm{T} / \mathrm{L}$ environment.

\section{ACKNOWLEDGEMENT}

The researcher would like to thank all those who participated in the research as research participants and all who rendered various services during the period of study. To all of you a big thank you

\section{REFERENCES}

[1] Khalid, M.U., (2008). Creating a Learner- Friendly Environment in all Adult and Non-Formal Education Literacy Centre. Journal of Nigeria National Council for Adult Education(NNCAE) 16, 151-158.

[2] Oyetunji, C.O., (2006).The Relationship between Leadership Styles and School Climate in Botswana Secondary Schools. University of South Africa (unpublished material).

[3] McBeath, J., \& Myers, K., (2008). Effective School Leaders. London: Pearson Education Ltd.

[4] Nsubuga, Y.K.K., (2008). Analysis of Leadership Styles and School Performance of Secondary Schools in Uganda (unpublished material)

[5] Wiza, M., \&Hlanganipai, N., (2014). "The Impact of Leadership Styles on Employee Organizational Commitment in Higher Learning Institutions." Mediterranean Journal of Social Sciences, Vol.5, No.4.

[6] Puni, A., Ofesi, S.B\&Okoe, A., (2014). "Effects of leadership Styles on Firm Performance in Ghana." International Journal of Marketing Studies, Vol.6, No.1.

[7] Kumar, S., (2018). Literature Review on Leadership, Leadership Theories, Style and Leadership Development. IMPACT: International Journal of Research in Business Management (IMPACT IJRBM) ISSN (P) 2347-4572; ISSN (E):2321-886x Vol.6 issue no. 6 pp13-24. 
An Empirical Investigation of Teacher Trainers' Perspective of Teaching and Learning Environment Existing in Selected Colleges of Education in Zambia

[8] Nyeri, M.M., (2015) Influence of Principals' Leadership Styles on School Climate in Secondary Schools in Ganze District- Kenya. Nairobi: University of Nairobi (Master Thesis)

[9] Organization for Economic Co-operation and Development (2009). From $21^{\text {st }}$ Learning Environment: Partnership for $21^{\text {st }}$ Century Skills.

[10] Creswell, J.M., (2012).Educational Research: Planning, Conducting and evaluating Quantitative and Qualitative Research ( $4^{\text {th }}$ edition.). Boston: Pearson.

[11] Ojokuku, R.M., Odetayo, T.A., \&Sajuyigbe, A.S (2012). "Impact of Leadership Styles on Organizational Performance. A Case Study of Nigerian Banks.” American Journal of Business and Management. Vol. 1, No.2, pp. 202-207.

\section{AUTHOR'S AUTOBIOGRAPHY}

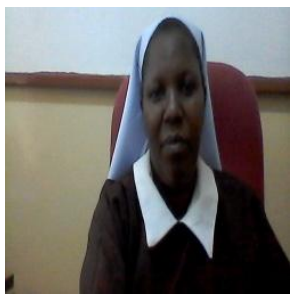

Sr Trinity, has been a teacher educator in various Colleges of Education in Zambia for the past 20 years. She is a PHD student at the University of Zambia. She obtained her Masters degree at Oslo University College in International Education and Development in Norway. She contributed a chapter in a book on HIV and AIDS and is currently working as lecturer at Kwame Nkrumah University in Zambia.

Citation: Sr. Trinity Rose Chikwanda, Dr. Gift Masaiti. "An Empirical Investigation of Teacher Trainers' Perspective of Teaching and Learning Environment Existing in Selected Colleges of Education in Zambia" International Journal of Humanities Social Sciences and Education (IJHSSE), vol 7, no. 2, 2020, pp. 1419. doi: http://dx.doi.org/10.20431/2349-0381.0702003.

Copyright: () 2020 Authors. This is an open-access article distributed under the terms of the Creative Commons Attribution License, which permits unrestricted use, distribution, and reproduction in any medium, provided the original author and source are credited. 